\title{
COVID-19 in children: clinical and epidemiological spectrum in the community
}

\author{
César García-Vera' ${ }^{1}$. Sandra Castejón-Ramírez ${ }^{2}$ - Elena Laín Miranda ${ }^{3} \cdot$ Rebeca Hernández Abadía $^{2}$. \\ María García Ventura ${ }^{4}$ - Elena Borque Navarro ${ }^{5}$. Patricia Rubio Sánchez ${ }^{2}$ Álvaro Baeta Ruiz ${ }^{5}$. \\ José María Mengual Gil ${ }^{6}$
}

Received: 9 July 2021 / Revised: 5 August 2021 / Accepted: 8 August 2021 / Published online: 18 August 2021

(c) The Author(s), under exclusive licence to Springer-Verlag GmbH Germany, part of Springer Nature 2021, corrected publication 2021

\begin{abstract}
Most publications on pediatric COVID-19 in Spain were performed at the beginning of the pandemic when some diagnostic tools were not widely available. This study aims to show the real spectrum of the infection based on wide detection of cases due to symptoms and contact tracing. A descriptive and analytical observational study was performed including pediatric cases (0 to 14 years) from the region of Aragón between May 12 and October 31, 2020. Diagnostics was by PCR detection of viral RNA, rapid antigen detection test, or positive IgG serology. There were 5933 positive children included. Of them, $49.03 \%$ were women. The mean age was $7.53 \pm 4.28$ years. The source of infection could not be determined in $17.8 \%$ of cases. As for the rest, was determined to be within the family environment in $67.8 \%$. The percentage of asymptomatic patients was $50.3 \%$. Among symptomatic patients, fever (58.1\%) and cough (46.7\%) were the most frequent symptoms. Hospitalization was required in $0.52 \%$ of infected, intensive care unit admission was on $0.05 \%$, and there was one death (0.02\%). Children under the age of one presented some symptoms more frequently $(71.6 \%$ vs $48.5 \%$; OR $2.68 ; 95 \%$ CI 2.08 to $3.45 ; p<0.001)$ and required more hospitalizations (3.9\% vs $0.34 \%$; OR $11.52 ; 95 \%$ CI 5.65 to $23.52 ; p<0.001)$.

Conclusion: In our environment, SARS-CoV-2 infection is like other mild respiratory viral infections in the population under the age of 15 . The contagion occurs mainly in the family environment, the number of asymptomatic is high, being the symptoms mild and the complications very infrequent.

\section{What is Known:}

- Pediatric infection produced by SARS-CoV-2 has manifested as a mild disease in relation to adult age, although with higher affectation at the youngest ages.

- Nearly all studies on epidemiology and clinical spectrum of the disease were conducted with patients diagnosed at the beginning of the pandemic. By then, diagnostic tools were only available in hospitals and in emergency units.

What is New:

- Once diagnostic means were available in primary care medicine and were used not only for the diagnosis of clinical symptoms of the patient, but for the tracing of case contacts, a much more precise approach to the epidemiology and clinical manifestations of the disease was allowed, as described in this study.
\end{abstract}

Keywords Asymptomatic diseases $\cdot$ Child $\cdot$ COVID-19 epidemiology $\cdot$ Pathology $\cdot$ Retrospective studies

\section{Abbreviations \\ CI Confidence interval \\ OR Odds ratio}

PCR Polymerase chain reaction

RNA Ribonucleic acid
Communicated by Peter de Winter

César García-Vera

cgarciavera@gmail.com

Extended author information available on the last page of the article

\section{Introduction}

In December 2019, Chinese health authorities identified a novel coronavirus as the etiological agent of a cluster of pneumonia cases, named SARS-CoV-2, which 
spread rapidly across the world. The disease, COVID19 , caused by this agent has been well characterized. However, in population sectors in which milder and asymptomatic presentations occur, such as children, the spectrum of clinical manifestations has not been fully described yet.

Clinical descriptions of COVID-19 in children under the age of 15 have mainly derived from hospitalized patients or emergency services. Large series of patients have been published mainly in Europe, the USA, and China [1-4]. A systematic review [5] which collected clinical data from 2914 children shows a proportion of asymptomatic children of $14.9 \%$, that varies from 0 to $53.5 \%$. Another systematic review published in 26 countries up to May 14, 2020 [6] collected data from 7780 pediatric cases revealing that $19.4 \%$ were asymptomatic. Additionally, another systematic review with data collected up to May 10, 2020, showed that, among symptomatic patients, $40 \%$ had a mild clinical presentation, $56 \%$ moderate, $3 \%$ severe, and $1 \%$ critical [7]. The description of clinical signs and symptoms of pediatric COVID-19 likewise varies greatly as described in the systematic review of Patel [5].

In Spain, the first published compilations [8] already showed divergences concerning respect to the real pediatric prevalence, higher in the first seroprevalence studies [9].

Diagnostic protocol radically changed in Spain from 12 May 2020 toward a broad detection of all suspected cases and their close contacts in primary care attention. This allowed to begin investigating what was really taking place in the community.

Aragón was one of the first regions in Spain and Europe to suffer a second pandemic wave (July-August 2020, data available at https://www.aragon.es/coronavirus/situacion-actual/ evolucion-diaria) and even a third one in October-November 2020. In these second and third waves, the 14-day cumulative incidence peaks in the overall population reached 616.3 and 1116.2 cases respectively per 100,000 inhabitants. This made possible to include a significant number of pediatric cases diagnosed thanks to either presenting symptoms or after a study of contacts of other cases.

The impression about the real presentation of this disease has changed since the performance of diagnostic tests has extended to the field of primary care, and contacts have been intensively tracked.

One only recent research study has been carried out in Spain including a representative sample of children from the community and its results differ from the previously published [10]. The objective of this study is to describe clinical and epidemiological data from the electronic clinical records of pediatric COVID patients in our community during the second and third pandemic waves.

\section{Materials and methods}

The observational, descriptive, and analytical study from all children diagnosed with COVID-19 in the public health system of the 3 provinces of the Community of Aragón (Zaragoza, Huesca, and Teruel) in Spain, in the period from May 12 to October 31, 2020.

In the public health system of Aragón, there are electronic health records for every user with clinical data (including radiological studies and complementary tests) from both hospital and primary care, collected and classified by episodes. Medical and nursing professionals are allowed to enter data. Access has also been allowed to professionals who have carried out the task of tracking cases. This enabled to extract clinical and epidemiological data from all the children of Aragón diagnosed with coronavirus infection during that period of time.

Children from 0 to 14 years with a positive diagnostic test performed in Aragón in the period previously described were included. Initially, a positive result in the RNA detection of SARS-CoV-2 by a polymerase chain reaction (PCR) from a respiratory sample of the upper or lower airways was considered a positive diagnostic test. In our community, the usual procedure is taking a nasopharyngeal sample with a swab. From October 7, antigen detection tests in nasopharyngeal samples were available in Aragón, and these positive tests were included as positive results as well. In addition, children with a positive determination for $\mathrm{IgG}$ against the spicule protein and/or against the SARS-CoV-2 nucleocapsid during that period, regardless of the result of the PCR or the antigen test, were included as infected by SARS-CoV-2.

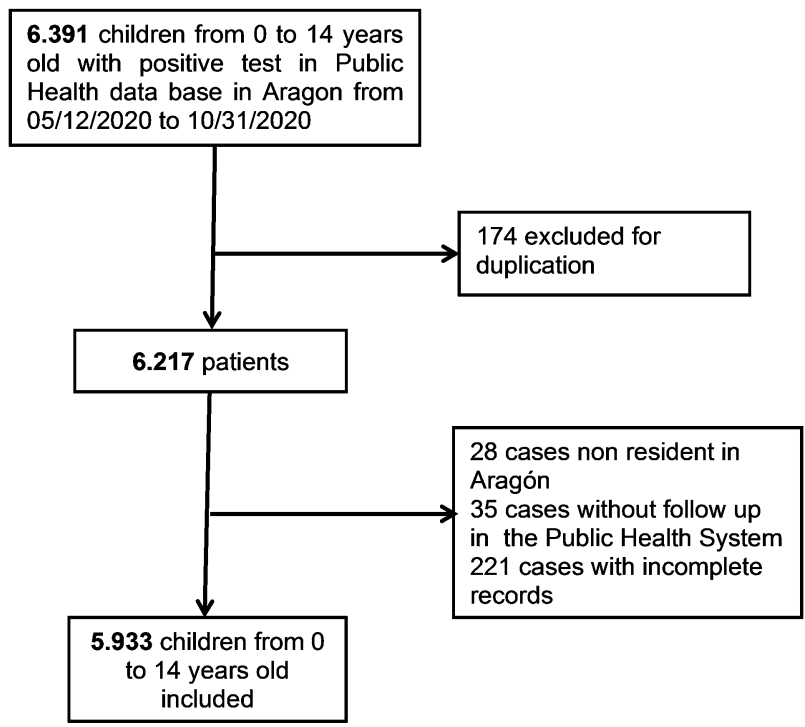

Fig. 1 Flow chart selection process 
Fig. 2 Number of cases and percentage distribution of COVID19 cases by age

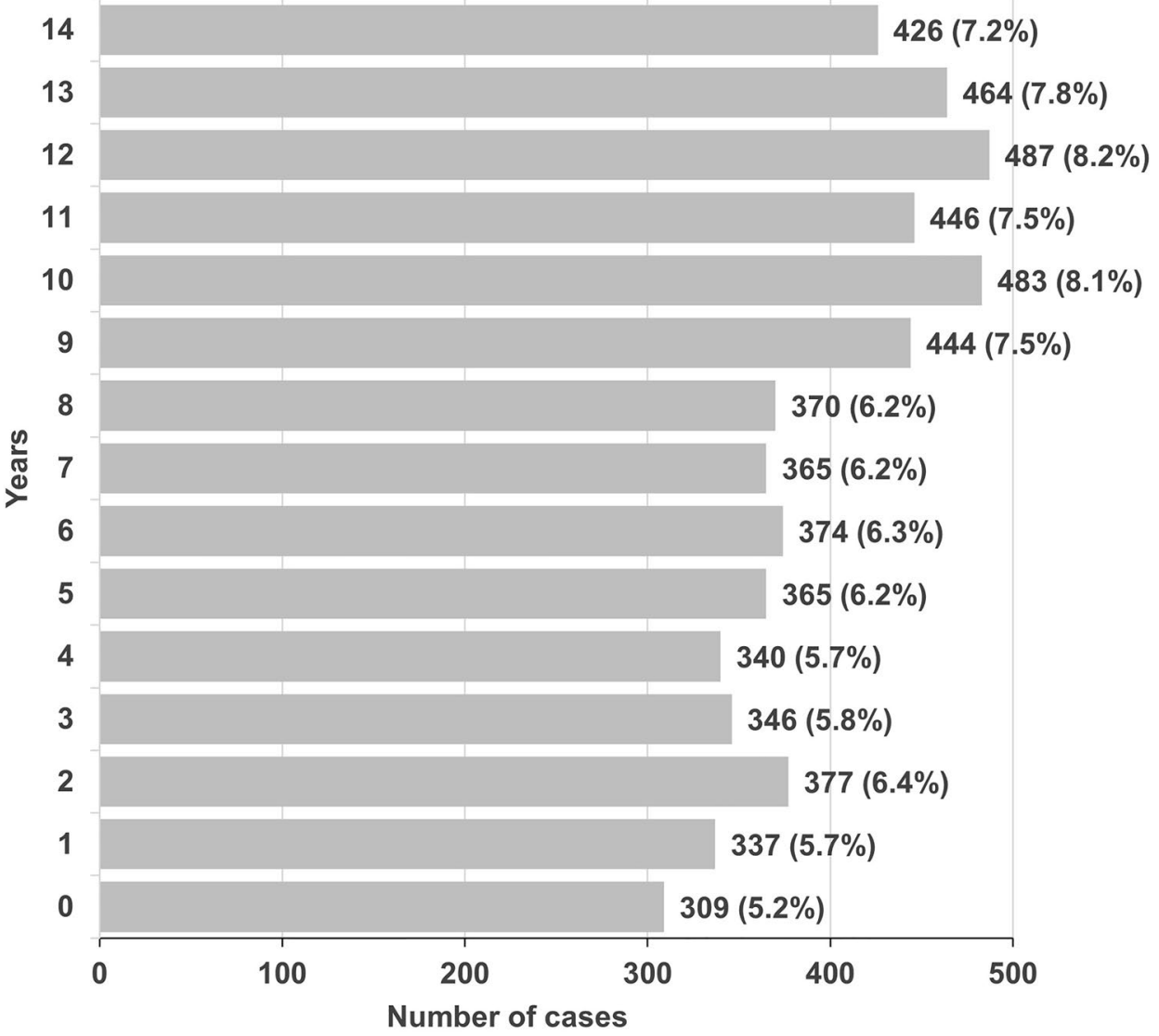

The criteria for performing a diagnostic test were either the presence of any sign or symptom compatible with the disease or having been in close contact with a positive case. Diagnostic tests (preferably PCR) have been performed on case contacts taking place $48 \mathrm{~h}$ before symptoms started or before taking the positive sample in asymptomatic patients.

The main variable was the presence or absence of any sign or symptom. The following variables were collected as secondary variables: age (classified as children under the age of 1, 1-4, 5-9, and 10-14), sex, income level of the person in charge of the child, possible source of infection, and evolution (considering the categories of asymptomatic, recovered at home, admitted to the hospital or ICU, and death). Other secondary variables were signs and symptoms of the following: fever (including its range and duration in days), cough, nasal congestion, odynophagia, dyspnea or respiratory distress, nausea or vomiting, diarrhea, abdominal pain, any skin manifestation, asthenia (general malaise or irritability), headache, myalgia, abnormal smell or taste, presence of pneumonia, and duration of symptoms in days (excluding days of discomfort, anosmia, or dysgeusia). Children who did not present any clinical sign or symptom in the 48-h period prior to the performance of the diagnostic test and up to 10 days after were considered asymptomatic.
Exclusion criteria were the following: children diagnosed by a diagnostic test other than the previously described, children with incomplete data in the registries, children who were not diagnosed or followed in the Public Health System (private medical assistance is estimated to be less than $10 \%$ of the pediatric population) and children residing in another region.

Anonymized data were recorded manually by reviewing the electronic medical records related to each patient's episode.

As for quantitative variables, measures of central tendency and dispersion were calculated depending on whether or not they fulfilled a normal distribution. As for qualitative variables, percentages and 95\% confidence intervals (95\% CI) were assessed. To analyze differences between variables, mean differences (MD) and odds ratios (OR) were calculated. To assess statistical significance among variables, the chi-square test, Student's $t$ test, analysis of variance, Fisher's exact test, Mann-Whitney test, or Kruskal-Wallis test were used. As statistical significance threshold, a value of $p \leq 0.05$ was adopted.

From May 12 to October 31, 6391 positive diagnostic tests for SARS-CoV-2 in children from 0 to 14 years old were notified in the Health Department database of the Public

\section{Results}


Table 1 Distribution of sources of infection

\begin{tabular}{ll}
\hline Source of contagion & $\boldsymbol{n}$ (proportion) \\
\hline Household acquisition & $\mathbf{4 0 2 1}(\mathbf{6 7 . 8 \% )}$ \\
Parent & $2747(46.3 \%)$ \\
Sibling & $450(7.6 \%)$ \\
Other family cohabitant & $805(13.6 \%)$ \\
Carer & $19(0.3 \%)$ \\
Outside acquisition & $\mathbf{8 5 5}(\mathbf{1 4 . 4 \% )}$ \\
School & $298(5.0 \%)$ \\
Friends and leisure & $278(4.7 \%)$ \\
Other & $279(4.7 \%)$ \\
Unknown & $\mathbf{1 0 5 7}(\mathbf{1 7 . 8 \% )}$ \\
Total & $\mathbf{5 9 3 3 ( 1 0 0 \% )}$ \\
\hline
\end{tabular}

Health Institution. Figure 1 presents the flow chart showing that 5933 children were assessed in the study, of which women were 2909 (49.03\%).

Figure 2 displays the proportion distribution by age. Mean age was $7.53 \pm 4.28$ years ranging from 0 days to 14 years, 11 months, and 24 days old. The mode was 12 years, and the median was 8 years old (interquartile range 4 to 11). The mean age for men $(7.60 \pm 4.33$ years old $)$ and women
(7.45 \pm 4.24$)$ did not differ significantly (MD: $0.15 ; 95 \%$ $\mathrm{CI}-0.07$ to $0.37 ; p=0.177$ ).

Regarding the diagnostic method used, 93.7\% (5561) of the children were diagnosed by PCR, 6.2\% (370) by rapid antigen detection test, and $0.03 \%$ (2) by serology (IgGpositive in venous blood).

Contacts known to be the source of infection are listed in Table 1 . Home and family environment contagion occurred in $67.8 \%$ of cases, school in 5\%, and contagion in recreational activities in $4.7 \%$. In $17.8 \%$ of cases, the source could not be identified. Unknown contagion source percentage among asymptomatic patients $(4.1 \%, 121$ cases) was significantly lower than in symptomatic patients $(31.6 \%, 922$ cases) (OR 10.86; 95\% CI 8.91 to $13.24 ; p<0.001$ ).

The two lowest income groups were significantly more frequent in the children included in this study (SARS-CoV2-positive cases), when compared to the regional population distribution (OR 1.97; 95\% CI 1.80 to $2.16 ; p<0.001$ in the lowest and OR $1.08 ; 95 \%$ CI 1.03 to $1.24 ; p=0.004$ in the following).

Asymptomatic children were 2969 (50.3\%), and symptomatic children were 2942 (49.7\%). Although the evolution of those infected did not differ by sex, it did differ by age groups, as shown in Table 2 . The mean age among
Table 2 Outcome of cases by age group

\begin{tabular}{|c|c|c|c|c|}
\hline Outcome & Age group & $n$ (proportion) & OR $(95 \%$ CI $)$ & $p$ Value \\
\hline \multirow[t]{5}{*}{ Asymptomatic } & $<1$ y/o & $87(28.34 \%)$ & Reference & \\
\hline & 1 to 4 & $711(50.86 \%)$ & $0.38(0.29$ to 0.50$)$ & $<0.001$ \\
\hline & 5 to 9 & $1052(55.19 \%)$ & $0.32(0.25$ to 0.42$)$ & $<0.001$ \\
\hline & 10 to 14 & $1119(48.72 \%)$ & $0.42(0.32$ to 0.54$)$ & $<0.001$ \\
\hline & Total & $2969(50.25 \%)$ & & \\
\hline \multirow{5}{*}{$\begin{array}{l}\text { Symptomatic, } \\
\text { not hospitalized }\end{array}$} & $<1$ y/o & $208(67.75 \%)$ & Reference & \\
\hline & 1 to 4 & $679(48.57 \%)$ & 2.22 (1.71 to 2.89$)$ & $<0.001$ \\
\hline & 5 to 9 & $849(44.54 \%)$ & $2.62(2.03$ to 3.38$)$ & $<0.001$ \\
\hline & 10 to 14 & $1172(51.02 \%)$ & $2.02(1.57$ to 2.60$)$ & $<0.001$ \\
\hline & Total & $2908(49.22 \%)$ & & \\
\hline \multirow[t]{5}{*}{ Admitted to hospital } & $<1$ y/o & $12(3.91 \%)$ & Reference & \\
\hline & 1 to 4 & $8(0.57 \%)$ & 7.07 (2.86 to 17.44$)$ & $<0.001$ \\
\hline & 5 to 9 & $5(0.26 \%)$ & 15.47 (5.41 to 44.22$)$ & $<0.001$ \\
\hline & 10 to 14 & $6(0.26 \%)$ & 15.53 (5.79 to 41.70$)$ & $<0.001$ \\
\hline & Total & $31(0.52 \%)$ & & \\
\hline \multirow[t]{5}{*}{ Admitted to ICU } & $<1 \mathrm{y} / \mathrm{o}$ & 0 & & \\
\hline & 1 to 4 & $1(0.07 \%)$ & & \\
\hline & 5 to 9 & $1(0.05 \%)$ & & \\
\hline & 10 to 14 & 0 & & \\
\hline & Total & $2(0.03 \%)$ & & \\
\hline \multirow[t]{5}{*}{ Exitus } & $<1$ y/o & $1(0.33 \%)$ & & \\
\hline & 1 to 4 & 0 & & \\
\hline & 5 to 9 & 0 & & \\
\hline & 10 to 14 & 0 & & \\
\hline & Total & $1(0.02 \%)$ & & \\
\hline
\end{tabular}


Table 3 Duration of signs and symptoms of active infection

\begin{tabular}{llc}
\hline Days & $\boldsymbol{n}$ & Proportion \\
\hline $\mathbf{< 1}$ & 32 & $1.3 \%$ \\
$\mathbf{1}$ & 358 & $14.3 \%$ \\
$\mathbf{2}$ & 564 & $22.5 \%$ \\
$\mathbf{3}$ & 605 & $24.1 \%$ \\
$\mathbf{4}$ & 296 & $11.8 \%$ \\
$\mathbf{5}$ & 207 & $8.3 \%$ \\
$\mathbf{6}$ & 129 & $5.1 \%$ \\
$\mathbf{\geq 7}$ & 317 & $12.6 \%$ \\
Total & $\mathbf{2 5 0 8} *$ & $\mathbf{1 0 0 . 0 \%}$ \\
\hline
\end{tabular}

*Data available in $86.1 \%$ (2508/ 2914) symptomatic patients

asymptomatic children $(8.10 \pm 4.03$ years old $)$ was significantly higher than that of hospitalized children $(4.79 \pm 5.01)$ (MD 3.31 years old; 95\% CI 1.47 to $5.15 ; p=0.001$ ) and like symptomatic children who did not require hospitalization $(7.99 \pm 4.51$ years old (MD 0.11 years old; $95 \%$ CI -0.11 to $0.33 ; P=0.325$ ).

Symptoms presence was significantly higher in the group of children under the age of one (71.7\%) compared to the rest of the groups (49.5\%), (OR 2.68; 95\% CI 2.08 to 3.45; $p<0.001)$. Children under the age of one (3.9\%) were admitted significantly more frequently than the rest of the age groups (0.3\%) (OR 11.52; 95\% CI 5.65 to $23.52 ; P<0.001$ ), among which there were no differences.

Symptoms duration (Table 3) was 1 day or less in $15.6 \%$ of cases, from 1 to 4 days in most cases and equal to or greater than 7 days in $12.6 \%$ (mainly due to persistence of cough and catarrhal symptoms).

Fever was recorded in $28.5 \%$ (1660) of infected children and in $58.1 \%$ of symptomatic patients. Only $10.1 \%$ (310) of symptomatic patients had a temperature greater than $38.5^{\circ} \mathrm{C}$. The duration of fever was 3 days or less in $81.6 \%$ (1465), and only 4\% (64) had a fever for 5 or more days.

Table 4 summarizes, in all symptomatic patients, the proportion of signs and symptoms by age group. Fever was significantly more frequent $(77.2 \%)$ in the group under the age of one (OR $2.61 ; 95 \%$ CI 1.38 to $2.62 ; p<0.001)$ and in the 1 - to 4-year-old group (64.8\%) (OR 1.45; 95\% CI 1.21 to $1.73 ; p<0.001)$ compared to the rest. Likewise, there was more frequency of cough in the group under the age of one (OR 2.30; 95\% CI 1.73 to $3.07 ; p<0.001$ ) and of nasal congestion (OR 2.10; 95\% CI 1.60 to 2.77; $p<0.001)$ in comparison to the rest of the ages. Symptoms reported by patients were, as expected, significantly more frequent in 5 to 9 and 10- to 14-year-old groups (odynophagia, headache, malaise, myalgia, anosmia, and dysgeusia). Dyspnea and respiratory distress were significantly more prevalent in the 10-14-year-old age group $(5.7 \%)$ compared to the rest of the ages (3.8\%) (OR 1.55; $95 \%$ CI 1.09 a $2.19 ; p=0.013)$. Regarding digestive manifestations in symptomatic patients, nausea and vomiting were significantly less frequent in those older than 9 years old $(4.8 \%)$ compared to the rest of children $(7.8 \%)$ (OR $0.58 ; 95 \%$ CI 0.42 to $0.80 ; p=0.001)$. Diarrhea was significantly more prevalent in the group under the age of one (18.2\%) and $1-4$ years old (17.1\%) (overall, $0-4$ years old $17.4 \%$, compared to those over four $10.7 \%$, OR $1.76 ; 95 \%$ CI 1.41 to $2.20 ; p<0.001)$.

Pneumonia diagnosis by imaging was found in 13 children $(0.22 \%$ of infected, and $0.44 \%$ of symptomatic children). It was significantly more frequent in 10 to 14 years

Table 4 Frequency of signs and symptoms in symptomatic patients by age group

\begin{tabular}{|c|c|c|c|c|c|}
\hline & $<1$ y/o & $1-4$ & 5-9 & $10-14$ & Total \\
\hline Fever & $166 / 215(77.2 \%)$ & $431 / 665(64.8 \%)$ & $471 / 833(56.5 \%)$ & $587 / 1138(51.6 \%)$ & $1655 / 2851(58.1 \%)$ \\
\hline Cough & $144 / 220(65.5 \%)$ & $364 / 685(53.1 \%)$ & $360 / 850(42.4 \%)$ & $499 / 1174(42.5 \%)$ & $1367 / 2929(46.7 \%)$ \\
\hline Nasal congestion & $116 / 220(52.7 \%)$ & $310 / 685(45.3 \%)$ & $260 / 850(30.6 \%)$ & $369 / 1174(31.4 \%)$ & $1055 / 2929(36.0 \%)$ \\
\hline Odynophagia & $26 / 218(11.9 \%)$ & $86 / 679(12.7 \%)$ & $218 / 850(25.7 \%)$ & $327 / 1174(27.9 \%)$ & 657/2921 (22.5\%) \\
\hline Headache & $5 / 216(2.3 \%)$ & $32 / 680(4.7 \%)$ & $224 / 850(26.4 \%)$ & $418 / 1174(35.6 \%)$ & $679 / 2920(23.3 \%)$ \\
\hline Dyspnea & $7 / 220(3.2 \%)$ & $21 / 685(3.1 \%)$ & $38 / 850(4.5 \%)$ & $67 / 1174(5.7 \%)$ & $133 / 2929(4.5 \%)$ \\
\hline Nauseas/vomits & $20 / 220(9.1 \%)$ & $59 / 685(8.6 \%)$ & $60 / 850(7.1 \%)$ & $56 / 1174(4.8 \%)$ & $195 / 2929(6.7 \%)$ \\
\hline Diarrhea & $40 / 220(18.2 \%)$ & $117 / 685(17.1 \%)$ & $93 / 850(10.9 \%)$ & $123 / 1174(10.5 \%)$ & $373 / 2929(12.7 \%)$ \\
\hline Abdominal pain & $18 / 217(8.3 \%)$ & $67 / 680(9.9 \%)$ & $125 / 850(14.7 \%)$ & $108 / 1174(9.2 \%)$ & 318/2921 (10.9\%) \\
\hline Skin manifestations & $3 / 220(1.4 \%)$ & $36 / 685(5.3 \%)$ & $31 / 850(3.6 \%)$ & $26 / 1174(2.2 \%)$ & 96/2929 (3.3\%) \\
\hline Malaise/irritability & $21 / 217(9.7 \%)$ & $60 / 681(8.8 \%)$ & $104 / 850(12.2 \%)$ & $230 / 1174(19.6 \%)$ & 415/2922 (14.2\%) \\
\hline Myalgia & $0 / 217(0.0 \%)$ & $15 / 679(2.2 \%)$ & $77 / 850(9.1 \%)$ & $146 / 1174(12.4 \%)$ & $238 / 2920(8.2 \%)$ \\
\hline Anosmia/dysgeusia & $1 / 216(0.5 \%)$ & $8 / 678(1.2 \%)$ & $46 / 850(5.4 \%)$ & $149 / 1175(12.7 \%)$ & $204 / 2920(7.0 \%)$ \\
\hline
\end{tabular}


old group ( 9 cases) than in the rest of the children (OR 3.38; 95\% CI 1.04 to $11.0 ; p=0.032)$. There were no differences by sex ( 6 out of 13 were women).

Thirty-one patients $(0.53 \%)$ required hospitalization, 3 of them required admission in the Intensive Care Unit, and only one died (a 3-month-old infant with a severe form of sphingolipidosis who died of respiratory failure). Three of the admissions (a 9-year-old girl and two 4 and 12-year-old boys) were diagnosed with multisystemic inflammatory syndrome related to SARS-CoV-2. This represents $0.05 \%$ of the total number of children with the infection.

The majority of admissions (41.9\%) were cases of COVID19 without complications. In $16 \%$ of admissions, the cause was respiratory failure associated or not with pneumonia. Gastroenteritis with risk of dehydration was the cause of admission in $16 \%$. Patients with chronic pathology (severe asthma, immunodeficiency, kidney transplantation, sickle cell anemia) were $12.9 \%$ of admissions. Coinfection was found in 4 of the 31 admissions: Campylobacter jejuni gastroenteritis, Streptococcus pyogenes pharyngotonsillitis, bronchitis with positive Rhinovirus detection in nasopharyngeal aspirate, and one bacteremia associated with venous catheter by Staphylococcus epidermidis.

\section{Discussion}

This research provides realistic knowledge of the clinical and epidemiological spectrum of SARS-CoV-2 infection in children from an economically developed country. Compared to previous research $[1-7,11-18]$, this study presents data from all the pediatric cases of Aragón, Spain, during the second and third waves of the pandemic. SARSCoV-2-positive cases were diagnosed by presenting suggestive signs or symptoms as well as by active tracking of close contacts of other positive cases.

During the pandemic in economically developed countries, there has been a unique diagnostic display. Due to the availability of diagnostic procedures for the entire community during the recruitment period, the reality of this infection in pediatric population could be studied. This enabled detecting numerous asymptomatic cases when studying close contacts of each new case.

The results of this study suggest that the real proportion of asymptomatic cases among infants is higher than the estimated in previous studies. In our sample, $50.3 \%$ of children under the age of 15 infected by SARS-CoV-2 did not present any symptoms during, at least, the first 12 days of infection. In the majority of studies prior to May 2020, around $14.9 \%$ were declared asymptomatic as shown in Patel's review [5]. However, in subsequent publications that included more cases diagnosed in the primary care setting, the rate of asymptomatic children rose to $43 \%$ [11], $35.9 \%$ [15], 47.2\% [10], and even $71.2 \%$ [17] (in this latest study of 6197 Italian children, the absence of symptoms was reported at the time of diagnosis). It must be pointed out that, in our series, the presence of symptoms is significantly higher in the group of children under the age of 1 (28.3\% asymptomatic) compared to the rest of the ages.

Regarding signs and symptoms of presentation, we agree with previous research $[3,5-7,10,14,15,18,19]$ in which fever and cough were the most prevalent (present in 58.1\% and $46.7 \%$, respectively, of the total of our symptomatic children). Digestive symptoms are not infrequent, as some publications have already exhibited [20, 21]. Cutaneous manifestations are only recorded in $3.3 \%$ of cases. Finally, it is outstanding that the low percentage of children who developed dyspnea or respiratory distress. Compared to the first publications (25\% [1], 13\% [3], 15.7\% [5], 11\% [7], $7.7 \%$ [16]), in our study, we found that only $4.5 \%$ of children have dyspnea or respiratory distress. This proportion is similar to the one described in the most recent studies (4.7\% [10], 3.2\% [15]). The diagnosis of pneumonia is also very uncommon ( $0.44 \%$ among symptomatic children), with unspecific symptoms and with the same radiological features as described in other publications [22]. Multisystemic inflammatory syndrome ( 1 in every 2000) is exceptional in our pediatric infection cases.

The most recent studies $[10,13,15,17,18]$ seem to modify the initial impression of greater affectation and severity among men, as described in adulthood. In this study, we do not find significant differences of infection rates when comparing both sexes, even when comparing the rate of symptomatic children or hospital admissions.

Unlike the case of older population, we are not facing a serious pediatric illness, but rather a common epidemic viral infection such as rhinovirus, adenovirus, or respiratory syncytial virus infections [23]. On its acute phase, it resembles a mild infection that does not produce signs nor symptoms in $50.3 \%$ of cases, and when it does, in 3 out of 4 cases, its duration is less than 5 days, only requiring admission in $0.52 \%$ and which fatality results in $0.017 \%$. However, it should be taken into account that infants under the age of one have greater susceptibility to have a symptomatic infection (71.7\%) and to require hospital admission (3.9\%).

An outstanding strength of this study is that it has been performed on the entire population of Aragón, not on samples from it. This allows to obtain data that are very close to reality. The diagnostic deployment carried out when SARS-CoV-2 infection is suspected, as well as the study performed on the possible contacts, helps understanding clinical and epidemiological spectrum of the disease, including the asymptomatic cases. The electronic system of clinical records in our setting made it possible to extract all the observations made by the physicians, nurses, and trackers who attended infected children. Additionally, there was a specific data collection template 
for all the confirmed cases, and the protocol for positive cases required follow-up (in person or via telephone) until the clinical and epidemiological discharge period for the patient had elapsed.

The weaknesses are those found in observational studies in which data are obtained from registries. Although the existence of electronic records using data collection templates reduces information and memory bias, these biases are greater than in studies carried out prospectively. Furthermore, the quality of this study may have been affected by the fact that records were collected by different professionals (primary care pediatricians, nurses, and social work personnel from several primary care centers as well as hospitals). In addition, those cases that were excluded due to lack of information or follow-up proceeded in a greater proportion from underprivileged sectors of the population, in some cases, associating a significant language barrier or social issues. Finally, it is important to remember that a greater number of infected cases could have been detected if active population screening were carried out, instead of only studying this infection in symptomatic patients or close contacts of a case.

Finally, and as the conclusions of this research, it seems that, until the end of 2020, with virus variants circulating until that moment, infection by SARS-CoV-2 in the pediatric population behaves like most respiratory transmitted epidemic pediatric viruses. Considering the proportion of asymptomatic patients, the symptoms and their duration, the rate of hospital admission, and fatality due to SARSCoV-2, this study suggests that, in childhood, we are facing a mild disease. The measures for its control in childhood are especially relevant due to the implications as they can be potential transmission vectors of the disease to the adult population.

\footnotetext{
Authors' contributions CG-V, ELM, and JMMG conceived the study, supervised data recovering, and performed statistics. Material preparation, data collection, and analysis were performed by SC-R, RHA, $\mathrm{MGV}, \mathrm{EBN}, \mathrm{PRS}$, and ABR. The first draft of the manuscript was written by CG-V and SC-R, and all authors commented on previous versions of the manuscript. All authors have read and approved the final manuscript.
}

Funding This study has been carried out using the own human and material resources of the Aragonese Health Service, without requiring specific funding.

Availability of data and material Complete data and material are available from the corresponding author, upon reasonable request.

\section{Declarations}

Ethics approval The study project was approved by the Research Ethics Committee of Aragón (CEICA, CP-CI PI20/613, Act No. 02/2021, of 01/27/2021).
Consent to participate/Consent for publication The Research Ethics Committee of Aragón authorized the use of registry data without the need for informed consent, since data were obtained retrospectively, and due anonymization was guaranteed.

Conflict of interest The authors declare no competing interests.

\section{References}

1. Götzinger F, Santiago-García B, Noguera-Julián A, Lanaspa M, Lancella L, Calò Carducci FI, Gabrovska N, Velizarova S, Prunk P, Osterman V, Krivec U, Lo Vecchio A, Shingadia D, Soriano-Arandes A, Melendo S, Lanari M, Pierantoni L, Wagner N, L'Huillier AG, Heininger U, Ritz N, Bandi S, Krajcar N, Roglić S, Santos M, Christiaens C, Creuven M, Buonsenso D, Welch SB, Bogyi M, Brinkmann F, Tebruegge M (2020) ptbnet COVID-19 Study Group. COVID-19 in children and adolescents in Europe: a multinational, multicentre cohort study. Lancet Child Adolesc Health 4(9):653-661. https://doi.org/10.1016/S2352-4642(20) 30177-2

2. Ludvigsson JF (2020) Systematic review of COVID-19 in children shows milder cases and a better prognosis than adults. Acta Paediatr 109(6):1088-1095. https://doi.org/10.1111/apa.15270

3. CDC COVID-19 Response Team (2020) Coronavirus disease 2019 in children - United States, February 12-April 2, 2020. MMWR 69(14):422-426. https://doi.org/10.15585/mmwr.mm6914e4

4. Dong Y, Mo X, Hu Y, Qi X, Jiang F, Jiang Z, Tong S (2020) Epidemiology of COVID-19 among children in China. Pediatrics 145(6):e20200702. https://doi.org/10.1542/peds.2020-0702

5. Patel NA (2020) Pediatric COVID-19: Systematic review of the literature. Am J Otolaryngol 41(5):102573. https://doi.org/10. 1016/j.amjoto.2020.102573

6. Hoang A, Chorath K, Moreira A, Evans M, Burmeister-Morton F, Burmeister F, Naqvi R, Petershack M, Moreira A (2020) COVID19 in 7780 pediatric patients: a systematic review. EClinicalMedicine 24:100433. https://doi.org/10.1016/j.eclinm.2020.100433

7. Meena J, Yadav J, Saini L, Yadav A, Kumar J (2020) Clinical features and outcome of SARS-CoV-2 infection in children: a systematic review and meta-analysis. Indian Pediatr 57(9):820-826. https://doi.org/10.1007/s13312-020-1961-0

8. Equipo COVID-19 (2020) RENAVE. CNE. CNM (Instituto de Salud Carlos III). Informe $\mathrm{n}^{\circ}$ 32. Situación de COVID-19 en España a 21 de mayo de 2020. https://www.isciii.es/QueHacemos/Servicios/ VigilanciaSaludPublicaRENAVE/EnfermedadesTransmisibles/ Documents/INFORMES/Informes\%20COVID-19/Informe $\% 20$ \% c2\%ba\%2032.\%20Situaci\%c3\%b3n\%20de\%20COVID-19\%20en\% 20Espa\%c3\%b1a\%20a\%2021\%20de\%20mayo\%20de\%202020.pdf . Accessed 05 July 2020

9. Pollán M, Pérez-Gómez B, Pastor-Barriuso R, Oteo J, Hernán MA, Pérez-Olmeda M, Sanmartín JL, Fernández-García A, Cruz I, Fernández de Larrea N, Molina M, Rodríguez-Cabrera F, Martín M, Merino-Amador P, León Paniagua J, Muñoz-Montalvo JF, Blanco F, Yotti R (2020) ENE-COVID Study Group. Prevalence of SARSCoV-2 in Spain (ENE-COVID): a nationwide, population-based seroepidemiological study. Lancet 396(10250):535-544. https://doi. org/10.1016/S0140-6736(20)31483-5

10. Soriano-Arandes A, Gatell A, Serrano P, Biosca M, Campillo F, Capdevila R, Fàbrega A, Lobato Z, López N, Moreno AM, Poblet M, Riera-Bosch MT, Rius N, Ruiz M, Sánchez A, Valldepérez C, Vilà M, Pineda V, Lazcano U, Díaz Y, Reyes-Urueña J, SolerPalacín P (2021) COPEDI-CAT research group. Household SARS$\mathrm{CoV}-2$ transmission and children: a network prospective study. Clin Infect Dis Mar 12:ciab228. https://doi.org/10.1093/cid/ciab228 
11. Bhuiyan MU, Stiboy E, Hassan MZ, Chan M, Islam MS, Haider N, Jaffe A, Homaira N (2021) Epidemiology of COVID-19 infection in young children under five years: a systematic review and meta-analysis. Vaccine 39(4):667-677. https://doi.org/10.1016/j. vaccine.2020.11.078

12. Swann OV, Holden KA, Turtle L, Pollock L, Fairfield CJ, Drake TM, Seth S, Egan C, Hardwick HE, Halpin S, Girvan M, Donohue C, Pritchard M, Patel LB, Ladhani S, Sigfrid L, Sinha IP, Olliaro PL, Nguyen-Van-Tam JS, Horby PW, Merson L, Carson G, Dunning J, Openshaw PJM, Baillie JK, Harrison EM, Docherty AB, Semple MG (2020) ISARIC4C Investigators. Clinical characteristics of children and young people admitted to hospital with COVID-19 in United Kingdom: prospective multicentre observational cohort study. BMJ 370 m3249. https://doi.org/10.1136/bmj.m3249

13. Otto WR, Geoghegan S, Posch LC, Bell LM, Coffin SE, Sammons JS, Harris RM, Odom John AR, Luan X, Gerber JS (2020) The epidemiology of severe acute respiratory syndrome coronavirus 2 in a pediatric healthcare network in the United States. J Pediatric Infect Dis Soc 9(5):523-529. https://doi.org/10.1093/jpids/piaa074

14. De Souza TH, Nadal JA, Nogueira RJN, Pereira RM, Brandão MB (2020) Clinical manifestations of children with COVID-19: a systematic review. Pediatr Pulmonol 55(8):1892-1899. https:// doi.org/10.1002/ppul.24885

15. King JA, Whitten TA, Bakal JA, McAlister FA (2021) Symptoms associated with a positive result for a swab for SARS-CoV-2 infection among children in Alberta. CMAJ 193(1):E1-E9. https://doi. org/10.1503/cmaj.202065

16. Liguoro I, Pilotto C, Bonanni M, Ferrari ME, Pusiol A, Nocerino A, Vidal E, Cogo P (2020) SARS-COV-2 infection in children and newborns: a systematic review. Eur J Pediatr 179(7):1029-1046. https://doi.org/10.1007/s00431-020-03684-7

17. Bellino S, Rota MC, Riccardo F Andrianou X, Mateo Urdiales A, Del Manso M, Punzo O, Bella A, Villani A, Pezzotti P (2021) COVID-19 Working Group. Pediatric COVID-19 cases prelockdown and postlockdown in Italy. Pediatrics 147(2):e2020035238. https://doi.org/10.1542/peds.2020-035238
18. Mizrahi B, Shilo S, Rossman H, Kalkstein N, Marcus K, Barer Y, Keshet A, Shamir-Stein N, Shalev V, Zohar AE, Chodick G, Segal E (2020) Longitudinal symptom dynamics of COVID-19 infection. Nat Commun 11(1):6208. https://doi.org/10.1038/ s41467-020-20053-y

19. Escosa-García L, Aguilera-Alonso D, Calvo C, Mellado MJ, Baquero-Artigao F (2020) Ten key points about COVID-19 in children: the shadows on the wall. Pediatr Pulmonol 55(10):25762586. https://doi.org/10.1002/ppul.25025

20. Wang J, Yuan X (2021) Digestive system symptoms and function in children with COVID-19: A meta-analysis. Medicine (Baltimore) 100(11):e24897. https://doi.org/10.1097/MD.0000000000024897

21. Ashktorab Y, Brim A, Pizuorno A, Gayam V, Nikdel S, Brim H (2021) COVID-19 Pediatric patients: gastrointestinal symptoms, presentations, and disparities by race/ethnicity in a large, multicenter US study. Gastroenterology 160(5):1842-1844. https://doi. org/10.1053/j.gastro.2020.12.078

22. Jimenez-García R, Nogueira J, Retuerta-Oliva A, Sainz T, CanoFernández J, Flores-Pérez P, Méndez-Echevarría A, VillalobosPinto E, Calleja-Gero L, Sanz-Santaeufemia FJ, Romero MP, Del Rosal T, Baquero-Artigao F, Grasa C, Calvo C (2021) Pneumonia in hospitalized children during SARS-CoV-2 pandemic. Is it all COVID-19? Comparison between COVID and non-COVID pneumonia. Pediatr Infect Dis J 40(3):e111-e113. https://doi.org/10. 1097/INF.0000000000003008

23. Galanti M, Birger R, Ud-Dean M, Filip I, Morita H, Comito D, Anthony S, Freyer GA, Ibrahim S, Lane B, Matienzo N, Ligon C, Rabadan R, Shittu A, Tagne E, Shaman J (2019) Rates of asymptomatic respiratory virus infection across age groups. Epidemiol Infect 147:e176. https://doi.org/10.1017/S0950268819000505

Publisher's Note Springer Nature remains neutral with regard to jurisdictional claims in published maps and institutional affiliations.

\section{Authors and Affiliations}

\section{César García-Vera ${ }^{1}\left[\right.$ - Sandra Castejón-Ramírez ${ }^{2}$ - Elena Laín Miranda ${ }^{3} \cdot$ Rebeca Hernández Abadía $^{2}$. María García Ventura ${ }^{4}$. Elena Borque Navarro ${ }^{5}$ Patricia Rubio Sánchez ${ }^{2}$. Álvaro Baeta Ruiz ${ }^{5}$. José María Mengual Gil ${ }^{6}$}

\author{
Sandra Castejón-Ramírez \\ scastejonr@gmail.com \\ Elena Laín Miranda \\ elenalainm@gmail.com \\ Rebeca Hernández Abadía \\ herabare@gmail.com \\ María García Ventura \\ mariagarciaventura90@gmail.com \\ Elena Borque Navarro \\ elenaborna@gmail.com \\ Patricia Rubio Sánchez \\ patrirub92@hotmail.com \\ Álvaro Baeta Ruiz \\ a.baeta11@gmail.com
}

José María Mengual Gil

pepebobes@gmail.com

1 Primary Health Care Center "José Ramón Muñoz Fernández”, Zaragoza, Spain

2 Hospital Materno-Infantil Miguel Servet, Zaragoza, Spain

3 Public Health Technician in the Health Region II of Zaragoza, Zaragoza, Spain

4 Primary Health Care Center "Valdespartera", Zaragoza, Spain

5 Hospital Clínico Universitario Lozano Blesa, Zaragoza, Spain

6 Primary Health Care Center "Delicias Sur", Zaragoza, Spain 